\title{
Applications of soil phosphate analysis for identification of activity areas at Doschkere, SE Bulgaria
}

\begin{abstract}
Human occupation enriches soils with phosphorus, which may provide a useful chemical tracer for site delineation in archaeological studies. In the present paper we use "spot-method" as well as extractible phosphorous soil content to estimate site boundaries and the activity areas at the region "Doschkere", situated near Malko Tranovo, Chirpan, SE Bulgaria.
\end{abstract}

Keywords: Phosphate soil analysis, site boundaries, activity area, bulgaria
Volume 3 Issue I - 2018

\author{
Boika Zlateva,' Boyan Dumanov, ${ }^{2}$ Miroslav \\ Rangelov ${ }^{3}$ \\ 'Faculty of Chemistry and Pharmacy, University of Sofia, Bulgaria \\ ${ }^{2}$ Department of Archaeology, New Bulgarian University, Bulgaria \\ ${ }^{3}$ Institute of Organic Chemistry with Centre of Phitochemistry, \\ Bulgarian Academy of Science, Bulgaria
}

Correspondence: Boika Zlateva, Faculty of Chemistry and Pharmacy, University of Sofia, Bulgaria, Tel 359899|326I7, Email ahbz@chem.uni-sofia.bg

Received: October 25, 2017 | Published: January 23, 2018

\section{Introduction}

Phosphorus (P) is unique among the elements in being a sensitive and persistent indicator of human activity. It has long been of interest to archaeologists because of its potential to inform them about the presence of past human occupation and to offer clues regarding the type and intensity of human activity. A wide variety of methods have been developed in both soil science and in archaeology to extract and measure phosphate content in soil, resulting in a tremendous amount of data and a wide array of interpretations, but also considerable confusion over appropriateness of methods and terminology. The reconstruction of the human activities areas of archaeological sites using soil phosphate analysis is well known technique. ${ }^{1-6}$ The purpose of the technique is the detection and delineation of archaeological sites, identification of the activity area, through the measurement of the quantity of phosphates present in the soil. ${ }^{3,4,7,8}$ Phosphates are chemical substances indicating specific human activities, such as the preparation and conservation of food, the deposit of liquid and solid wastes and burial. The detection can be executed directly in the field ("spot method") or else in the laboratory on soil samples. In the latter case, the total or available phosphate content is normally measured. The main advantage of the technique in the field ("spot method") is the immediate response to traces of specific organic materials. The aim of this investigation is to obtain activity areas in the archaeological excavation as well as to find the areas of habitation near to the archaeological complex. The excavation was in the field Doschkere, near to Malko Tranovo, South-eastern Bulgaria, where evidence of ancient occupancy is absent. The territory of South-west direction, situated in the modern forest in distance at $500 \mathrm{~m}$ of the excavated archaeological complex was investigated for human activities using soil phosphate data.

\section{Archaeological background}

The archaeological site is situated near village Malko Tranovo, (SE Bulgaria) and it is registered for archaeological investigations at the 2000 year. Because the place is located of highway under of construction the excavations were carried out in the autumn of 2003 year. The archaeological excavations were taken only the territory of the highway "Trakia", in $15 \mathrm{~km}$ east direction from Chirpan (Figure 1, http://www.api.bg/index.php/bg/karti/republikanska-ptna-mrezha/). The primary data indicated different ceramic remains, which had been hand produced as well as using ceramic wheel. The mostly ceramics remains are dated from the Roman period.

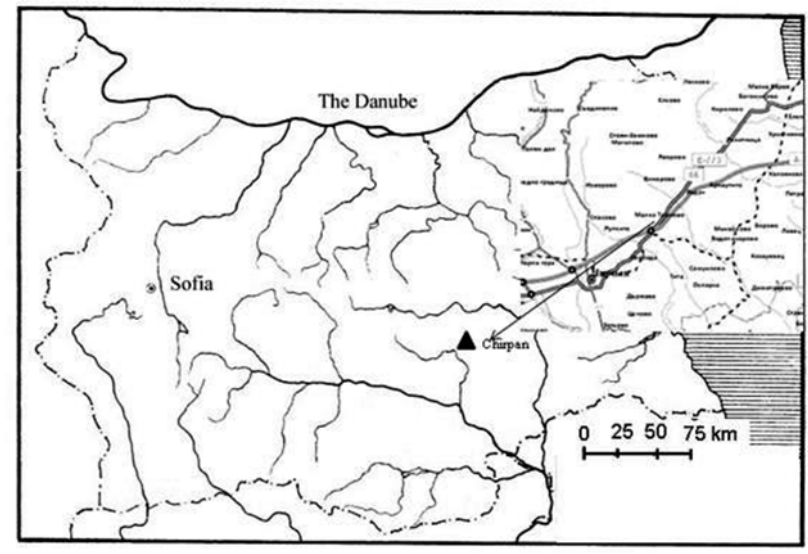

Figure I Map of the investigated area.

The archaeological region is with slope in South-Southeast direction and cover area to about $3000 \mathrm{~m}^{2}$ (Figure 2). After the preliminary researches was found a wall in the North-South direction preserved in one, two lines. Subsequent excavations revealed the boundaries of the complex, which is located partially within highway. The complex consist five chain buildings incorporated around central inner courtyard. The founded archaeological troves are building ceramics, tiles (tegulae and imbreces) and glass windows. The storage vessels (dolium) as well as the fragments of pitos are representing the ceramics of everyday use and generally were dated 3rd-4th c. AD. There were also found flints, iron nails and different small archaeological fragments. Outside the investigated field of excavations nearest to the wall of the complex was found buckle from type mostly circulated at the second half of 4th c. AD. More 
accurate dating was done by found coins; the earliest of them were from the serial of Emperor Konstantin I and the oldest are from Emperor Valentinian I (also known as Valentinian the Great 364 to 375 or $378 \mathrm{AD}$ ). The complex to reveal outside the archaeological excavation area is consists probably (?) of several buildings, a rural area or perhaps it is part of a larger complex. The coins found there show the end of the complex's life in the 70 s of the 4th century AD, which are related to the Gothic invasions of this region.

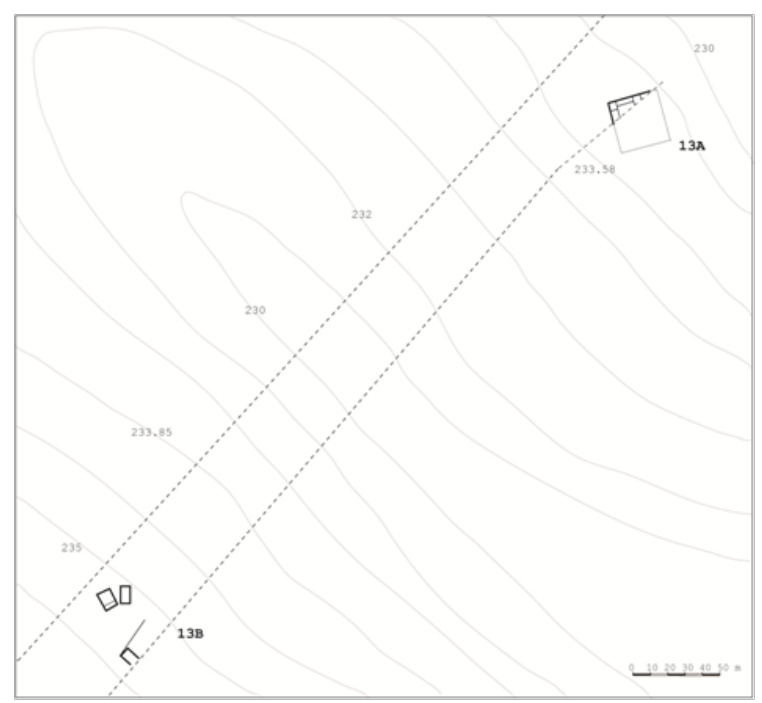

Figure 2 Plan of the excavated archaeological complex I3A.

\section{Materials and methods}

There are many investigations of the soil phosphate chemistry in archaeology (described clearly in Holliday) here the field classical "spot method" modified by Perrson ${ }^{10}$ was used and laboratory measurement of the available phosphate-content was performed. ${ }^{10} \mathrm{~A}$ stratified sampling was performed over the excavation areas and the outside region of interest. The total number of 172 soil samples were collected along predetermined transect lines. After using the "spotmethod" in the field, 70 samples (about $0.5 \mathrm{~kg}$ each) with highest phosphate content (i.e. highest intensive blue color) were collected from the archaeological layer (in depth $30-40 \mathrm{~cm}$ ) for instrumental analysis of $\mathrm{P}$ concentration. The taken samples for laboratory measurement included samples from the archaeological excavation area as well as from the territory in SW direction, situated in the modern forest in distance at $500 \mathrm{~m}$ of the excavated archaeological complex to find settlement boundaries (Figure 2). Control samples from an off-site area were also collected. Sub-samples of $20 \mathrm{~g}$ from the collected soil samples were dried to constant weight $\left(48 \mathrm{~h}, 30^{\circ} \mathrm{C}\right)$ and were cleaned up carefully from stones and rootlets. Subsequently the samples were grounded in an agate mortar and the powder was passed through a $2 \mathrm{~mm}$ sieve and then $0.1 \mathrm{~mm}$ sieve.

The analysis was performed as follows: about $0.4 \mathrm{~g}$ of sample was extracted for $20 \mathrm{~min}$ with $2 \mathrm{~N} \mathrm{HCl}$ and citric acid. The use of citric acid is suitable for the podzolic soils with high contents of $\mathrm{Fe}^{3+}$ (typical for the region of interest) because there is strong tendency of forming citric complexes with $\mathrm{Fe}^{3+}$, without extensively releasing organically bonded phosphorous. Finally about $0.01 \mathrm{~g} \mathrm{SnCl}_{2}$ was added to reduce $\mathrm{Fe}^{3+}$ to $\mathrm{Fe}^{2+}$. The color strength is equivalent to $\mathrm{P}$ content and is measured by spectrophotometer Specol 11 at $815 \mathrm{~nm}$ (blue color). The percent transmittance was converted to $\mathrm{mg} / \mathrm{L}$ by standard curve and appropriate dilution factors were used to convert the concentration values to $\mathrm{mg} \mathrm{P} / \mathrm{kg}$ soil.

\section{Results and discussion}

The results from the chemical analyses are displayed as scatter plots, describing the Pav vs sampling location. In Figure 3 are present the results of phosphate content for the excavation archaeological complex (structure 13 A forms Figure 2 in details) were marked points corresponding to the sampling places. In Figure 4 is given the data for the investigated field in SE direction from the archaeological complex. Some parts of the samples were taken in the opposite direction to obtain background level of phosphorous at the undisturbed natural soils. Although the field had been fertilized in the $60 \mathrm{~s}-70$ s of 20 th c. we tried to estimate the level of the archaeological phosphate content using collected data of the disturbed and undisturbed regions and statistical treatment after z-normalization of them. Obviously there is a serious lack of compromising of the data but on the basis of ANOVAs statistical treatment the total variances between the groups ${ }^{11}$ are bellow the accuracy of the using method (bellow $0.1 \%$ ) which is an evidence of the relevance of the procedure.

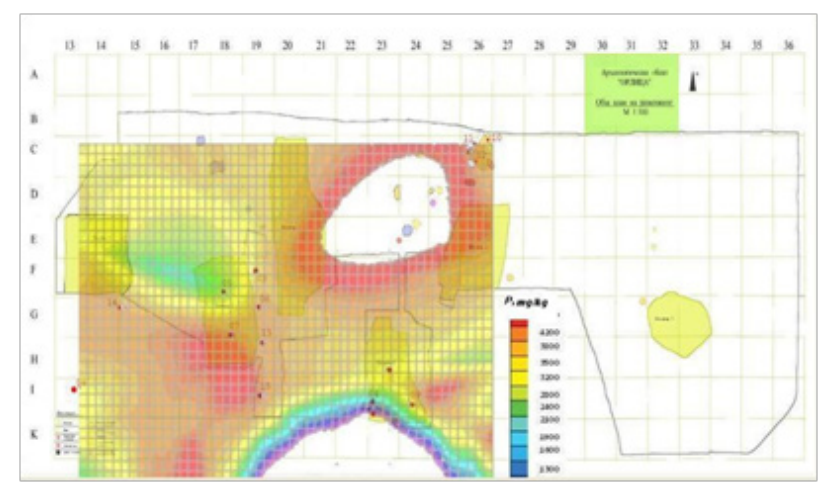

Figure 3 Plan of the archaeological complex I3 A with excavated structures and mapped on it the concentration of the phosphate concentration $(\mathrm{mg} / \mathrm{kg})$.

The distribution of phosphorous concentrations from the different locations illustrates the variability quite well (Figure 3) (Figure 4). These patterns of variation an element concentration of the soils provide the basis for numerical classification. The samples from excavation site are compared to and matched with the samples from site of interest and off-site samples to identify the activity areas as well as the site boundaries.

\section{Activity areas}

At the excavation site 3 groups can be identified (Figure 3) which matched well to ethno-archaeological defined activity areas. The first group is characterized with relatively low concentration of phosphorous but higher than off-site control and corresponded to samples collected near to walls, broken tiles and the stone aggregations. These results may suggest zones with high traffic or very low activity, or that this area may have been reserved for any activities that did not involve using of organic substances. The concentrations of the second and third groups are extremely higher than all of the rest samples despite there are the significantly differences between the groups. Group 2 is connected with a general occupation and it is characterized with highest concentration of phosphorous in area of archaeological excavation. The highest concentration of phosphorous is obtained around to the pit in Northeast edge of the excavation area, in House 3 and 4 and in South direction of House 4. 


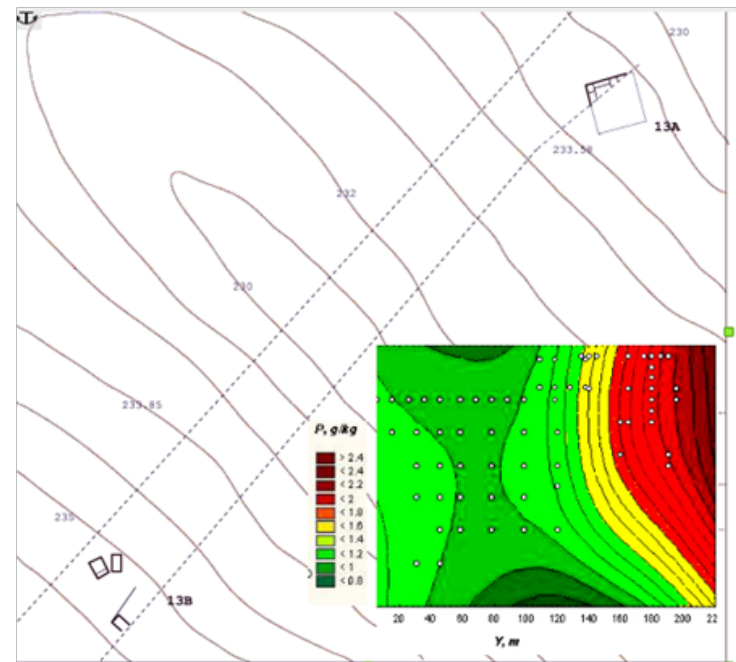

Figure 4 Scaterplot of the data of phosphate content and sampling points in the SW area to the excavation archaeological complex. The isopleths lines represent available phosphate concentration $(g / \mathrm{kg})$ of the SW area and the direction of potential site borders are indicated (mark with black line).

Together with archaeological finds jars and vessels, this suggests that these buildings were connected in activities related to the preparation and consumption of foods and may be beverages. The high concentration of phosphate-content in South direction from House 4 as well as around the pit in the Northeast edge of the area may be connected with human waste. The third group is consisting of the samples, collected near to Eastern part to the House 6 and in the House 1. The relatively low phosphate-content compared to the second group and at the same time higher concentration compared to the first group samples, may be associated with domestic activities grinding stones, stone tools, etc. or craft manufactures.

\section{Settlement boundaries}

At a distance of $500 \mathrm{~m}$ in South-west direction from the excavation area had been exploited region of about $150 \mathrm{~m}^{2}$ for eventually define settlement boundaries by laboratory measurements of P-content. The data of used in the field "spot method" shows that there is enrichment in soil phosphate in North-eastern edge of the investigated area and the collected samples were additionally analyzed in the laboratory to clarify the results.

The changes of phosphate-content in North-eastern edge are smooth and show slightly increasing in direction to the archaeological complex (Figure 4). The level of phosphate in this region is in the same concentration ratio as determined for the second group in the archaeological complex (i.e. medium high concentration of P-content). On this basis, we can assume that (probably) in this area there had been human activity. All of the rest samples collected from the investigated region shows background level of phosphate. Unfortunately only on this basis is very difficult to conclude that we have found South-west settlement boundary considering the limited number of the samples and with respect to the existing modern forest in the area. It was not possible to continue the investigation in the same direction because there are contemporary human activities, i.e. used roads and farmlands. At the same time no doubt that higher phosphate content is in resulting of human activities in the past and together with the archaeological fragments, mainly ceramic, which are similar to vessels excavated from the archaeological complex, it is possible to assume that there had been human activity of this area in the past.

\section{Conclusion}

The results of our analyses indicate that soil chemical signatures of midden materials may be very important in decoding the various waste deposits of the ancient people. The obtained results from this investigation despite limited number of the samples and the impossibility to clarify the settlement boundaries is an example for the applicability of the soil phosphate method in the archaeology. The combination between "spot method" using in the field and laboratory measurement of P-content can be used to identify areas of prior human occupation. In field situations where vegetation is dense and surface visibility is poor, this technique can offer a quick and inexpensive assessment of P-content in the soil and ancient site presence when other investigative approaches are not feasible. The data demonstrate the possibilities of the method for reconstruction of the activity area, the way of the utilization of the areas, settlement boundaries and may be useful to provide guidelines for future studies. ${ }^{12-14}$

\section{Acknowledgements}

None.

\section{Conflict of interest}

Author declares that there is no conflict of interest.

\section{References}

1. Bethell PH, Mate I. The use of soil phosphate analyses in archaeometry: Anritique. In: Henderson J, editor. Scientific Analyses in Archaeology and its interpretation, Exeter Short Run Press, UK; 1989. p. 1-29.

2. Sánchez C, Lizcano R. Phosphorus analysis at archaeological sites: an optimization of the method and interpretation of the results. Archaeometry. 1996;38(1):151-164.

3. Middelton WD. Identifying chemical activity residues on prehistoric house floors: a methodology and rationale for multi-elemental characterization of a mild acid extract of anthropogenic sediments. Archaeometry. 2004;46(1):47-65.

4. Parnell JJ, Terry RE, Nelson Z. Soil chemical analysis applied as an interpretive tool for ancient human activities in Piedras Negras, Guatemal. Journal of Arcaeological Sciences. 2002;29(4):379-404.

5. Wells EC. Investigating activity patterns in prehispanic plazas: weak acid-extraction icp-aes analysis of anthrosols at classic period El Coyote, Northwestern Honduras. Archaeometry. 2004;46(1):65-84.

6. Wells EC, Terry RE, Parnell JJ, et al. Chemical analyses of ancient anthrosols in residential areas at Piedras Negras, Guatemala. Journal of Archaeological Sciences. 2000;27(2):449-462.

7. Bjelajac VE, Lubyrose R. Validation test of a field-based phosphate analysis technique. Journal of Archaeological Science. 1996;23(2):243-248.

8. Cabanes D, Gadot Y, Cabanes M, et al. Human impact around settlement sites: a phytolith and mineralogical study for assessing site boundaries, phytolith preservation and implications for spatial reconstructions using plant remains. Journal of Arcaeological Sciences. 2012;39(8):26972705.

9. Eidt RC. Detection and examination of anthrosols by phosphate analysis. Science. 1977;197(4311):1327-1333. 
10. Perrson KB. Soil phosphate analysis: a new technique for measurement in the field using a test strip. Archaeometry. 1997;39(2):441-443.

11. Stat Soft Inc. STATISTICA (data analysis software system), version 8.0 . 2007.

12. Kuleff I. Archaeometry (in bulg). Sofia University, USA; 2012. p. 86.
13. Holliday VTA, Gartner WG. Methods of soil P analysis in archaeology. Journal of Archaeological Sciences. 2007;34(2):301-333.

14. Solecki RS. Notes on soil analysis and archaeology. Journal of American Antiquity. 1951;16(3):254-256. 